\title{
Synthesis on a type of polycarboxylate superplasticizer under room temprature
}

\author{
Xing $\mathrm{Li}^{1, \mathrm{a}}$, Minghua Yuan ${ }^{1}$, Chong sun ${ }^{1}$, Jinwen Wang $^{1}$ \\ ${ }^{1}$ China Construction Ready Mixed Concrete Co. Ltd, Wuhan 430205, China, \\ aleexingbridge@yeah.net,
}

Keywords: polycarboxylate superplasticizer, temprature, fluidity of cement paste, concrete slump

Abstract. This investigation was undertaken to evaluate a new kind of polycarboxylate superplasticizer .Used polyoxyethylene ether (TPEG), acrylic acid (AA) functional monomer (A)and as the monomer, hydrogen peroxide (H2O2) as initiator, Vitamin C (Vc)as reducing agent, TGA as chain transfer agent, synthesised polycarboxylate superplasticizer with high water reducing rate under $15 \mathrm{C} \sim 27 \mathrm{C}$. The effect of admixtures on fluidity and concrete slump were discussed in this paper..This investigation also evaluated the influence of different serials of polyoxyethylene ether, the dosage of hydrogen peroxide $\left(\mathrm{H}_{2} \mathrm{O}_{2}\right)$ and Vitamin $\mathrm{C}(\mathrm{Vc})$.

\section{Introduction}

Concrete is the world's the largest building materials, widely used in various construction projects. Chemical admixture plays an important role in concrete, it could reduce water consumption and dispersion of cement particles, increase the strength of concrete, etc[1].

Polycarboxylate superplasticizers are the most important water reducing agent[2-4]. It replaced first generation and second generation water reducing agent, such as lignin sulfonate, naphthalene water reducer and aliphat sulfate water reducer. It solved fast slump loss of naphthalene water reducer and delayed coagulation of lignin sulfonate[5]. In terms of chemical structure,these polymers have lots of advantages: better fluidity and slump flow with low dosage of PCs, wide adaptability for cement,higher water-reducing efficiency,large freedom of molecular structure,more synthesis technology,more room for improvement[6-7].

Most polycarboxylate superplasticizers adopt radical polymerization under 60-80C, use persulfate as initiator[8-9]. Quantity of heat was needed during its synthesis. This could bring environment pollution, consume lots of energy[10]. Sythsis under room tempreture mean a lot to save energy and reduce the pollution of the environment.

\section{Experimental}

\subsection{Chemicals and Equipment.}

Prenyl alcohol ethoxylates (TPEG, Liaoning Kelong Chemical Co. LTD), Acrylic acid (AA,Wuhan Zhonghua Yongye Chemical Co. LTD), Hydrogen peroxide (H2O2, Wuhan chemical Co. LTD), Vitamin C (Vc, Wuhan zhongxin materials Co.LTD), Chain transfer agent (TGA, Changzhou Yurong Chemical Co.LTD) ,sodium hydroxide( $\mathrm{NaOH})$, HuaXin cement,P.O42.5,WuGang II flyash, WuXin S95 silica fume. Cement paste mixer,NJ-160A,WuXi JianYi equipment Co. LTD ; Single horizontal-axis laboratory concrete mixer,HJW-60,ShenYang JuLin equipment Co. LTD.

\subsection{Synthesis Process.}

Put water and TPEG into a flask, and stirried until the end of experiment; wait until TPEG dissolved, then added the $\mathrm{H}_{2} \mathrm{O}_{2}$ at $60^{\circ} \mathrm{C}$, and dripped the AA, functional monomer (A), Vitamin $\mathrm{C}$ (Vc)and TGA solution; keep stirring for certain hours, then added the sodium hydroxide and water, and adjusted $\mathrm{pH}$ of the new product about 7; The new product would been gotten and its solid content was $40 \%$. 


\subsection{Measurement.}

The fluidity of cement slurry was tested according to Chinese Standard (GB/8077-2000). The water-cement ratio is 0.29 ,PCs dosage is $0.13 \%$.

\section{Results and Discussion}

\subsection{Determination of monomer type}

F108 and TJ-188 are synthesised by imported initiator, while F1088 and TJ-188C are synthesised by domestic initiator. The front two kinds of monomers are more active than back ones. The table shows F108 and TJ188 is more suitable for this method.

Table.1 Fluidity of cement paste with different monomer condition of PCs

\begin{tabular}{|c|c|c|}
\hline Type & 0min Slump flow(mm) & 60min Slump flow(mm) \\
\hline $\begin{array}{c}\text { F108(Liaoning Kelong Chemical Co. } \\
\text { LTD ) }\end{array}$ & $240 / 565$ & $230 / 560$ \\
\hline $\begin{array}{c}\text { F1088(Liaoning Kelong Chemical Co. } \\
\text { LTD ) }\end{array}$ & $240 / 560$ & $220 / 480$ \\
\hline $\begin{array}{c}\text { TJ188(ShangHai TaiJie Chemical Co. } \\
\text { LTD ) }\end{array}$ & $250 / 590$ & $230 / 580$ \\
\hline $\begin{array}{c}\text { TJ188C(ShangHai TaiJie Chemical Co. } \\
\text { LTD ) }\end{array}$ & $235 / 540$ & $225 / 470$ \\
\hline
\end{tabular}

\subsection{Determination of initiator Dosage}

We can see from figure 1, with all other conditions being equal, concrete has the best dispertion performance when the dosage of initiator is $0.015 \mathrm{~mol}$. This is because low dosage of initiator causes little active centre, reaction is not complete; as high dosage of initiator causes too many active centre, the molecular weight is too small to the disadvantage of space steric hindrance.

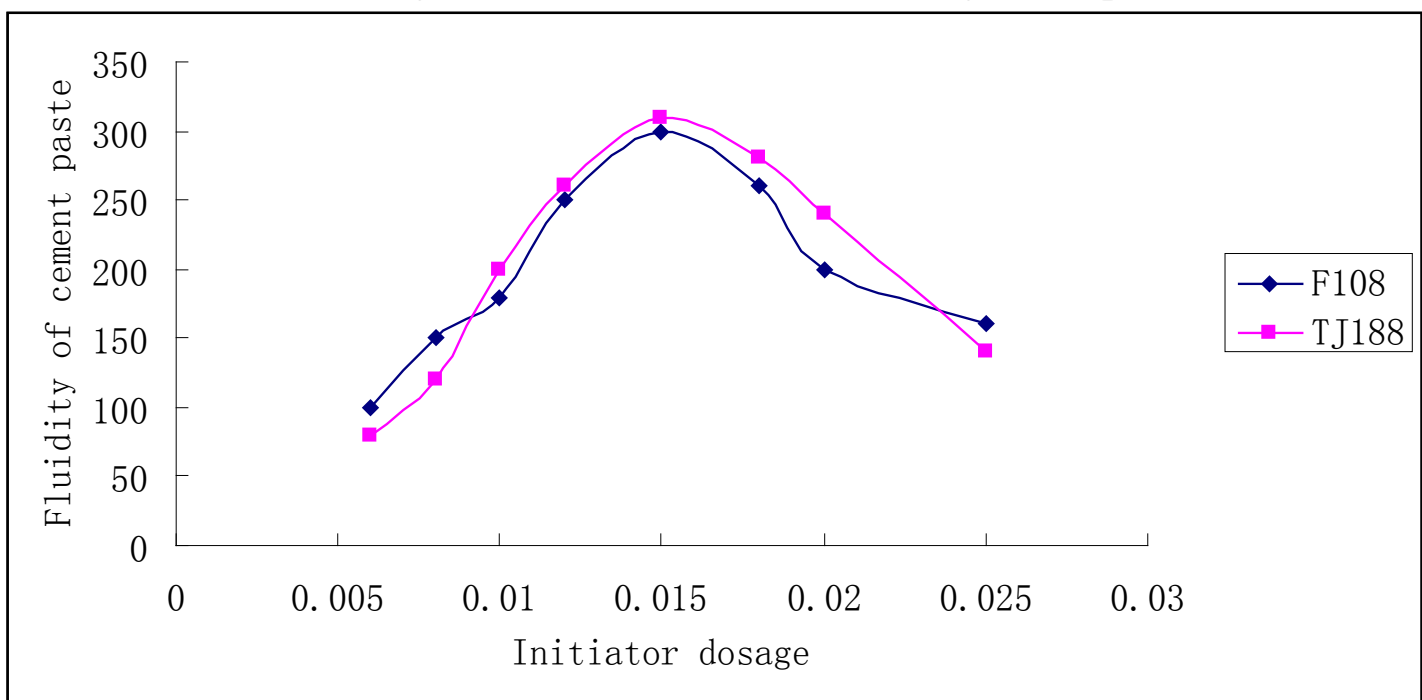

Fig.1 Fluidity of cement paste with different density of initiator

\subsection{Determination of reaction time}

According to time temperature equivalence principle, we studied the influence of reaction time on the properties of polycarboxylate superplasticizers. We can see from figure 2 that $4 \mathrm{~h}$ is the most suitable reaction time: reaction is not complete less than $4 \mathrm{~h}$, it is helpless more than $4 \mathrm{~h}$. 


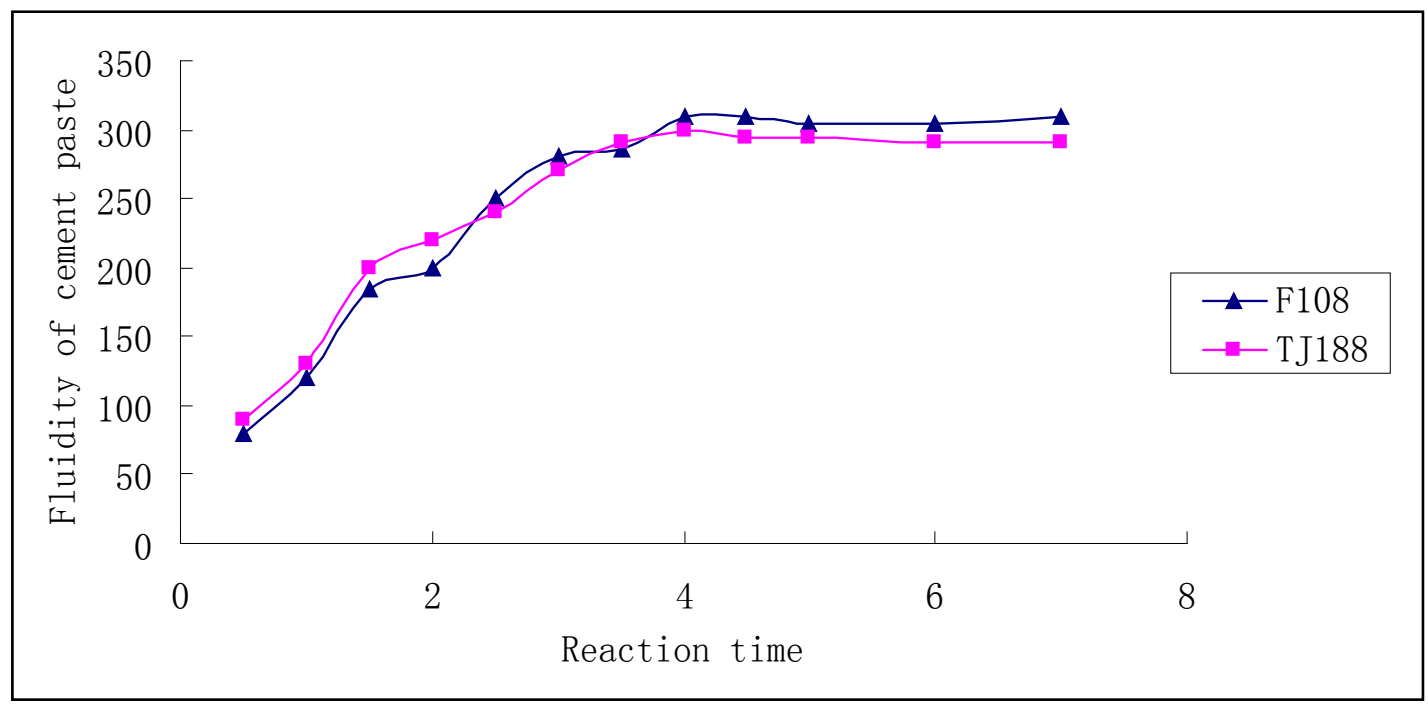

Fig.2 Fluidity of cement paste with different reaction time

\section{Conclusion}

By discussing various factors that impact the performance of PCs, we confirm a suitable process conditions which a new type of polycarboxylate superplasticizer was synthesized under room tempreture. The influencing factors of reaction include proportion of initiator concentration and reaction time. It is possible to realize industrial production under room tempreture, then save energy and reduce the pollution of the environment.

\section{References}

[1] J. Witt, J. Plank, A Novel type of PCE possessing Silyl Functionalities, In print.

[2] Liping G, Shaofeng W, Anfu Z, et al. Determination of Residual Monomers in Polycarboxylate Superplasticizer Using High Performance Liquid Chromatography[J]. Journal of Wuhan University of Technology(Materials Science Edition), 2011, (3): 439-442.

[3] Yamada K, Takahashi T, Hanehara S, et al. Effects of the Chemical Structure on the Properties of Polycarboxylate-type Superplasticizer[J]. Cement and Concrete Research, 2000, 30(2): 197-207.

[4] K.Yamada,S.Ogawa, S, Hanebara, Controlling of the Adsorption and Dispersing Force of Polycarboxylate type Superplasticizer by Sulfate ion Concentration in Aqueous Phase, Cem. Concr. Res.31(2001) 375-383.

[5] Plank J, Brandl A, Zhai Y, et al. Adsorption Behavior and Effectiveness of Poly(N,N-dimethylacrylamide-co-Ca 2-acrylamido-2-methylpropanesulfonate) as Cement Fluid Loss Additive in the Presence of Acetone-formaldehyde-sulfite Dispersant[J]. Journal of Applied Polymer Science, 2006, 102(5): 4341-4347.

[6] Guo M, Que C, Wang C, et al. Multifunctional Superparamagnetic Nanocarriers with Folate-mediated and pH-responsive Targeting Properties for Anticancer Drug Delivery[J]. Biomaterials, 2011, 32(1): 185-194.

[7] Lowke D, Kränkel T, Gehlen C, et al. Effect of Cement on Superplasticizer Adsorption, Yield Stress, Thixotropy and Segregation ResistanceDesign, Production and Placement of Self-Consolidating Concrete[J]. 2010, 1: 91-101.

[8] C. Li, H. Wang, H. Wu, et al, Synthesis and performance a slowly-released type polycarboxylic water-reducers, Baton Chinese Edition-ready-mixed Concrete, 10 (2010) 27-28. 
[9] Z. Wang, Polycarboxylate Superplasticizer--Preparation Performance and Application, China Building Industry Press, Beijing, (2009) 153-201.

[10] S. Li, Q. Yu, J. Wei, Effect of molecular structure of polycarboxylate water reducers on hydration of cement, Journal of the Chinese Ceramic Society, 4 (2012) 614-618. 